\title{
Sexuality and obesity, a gender perspective: results from French national random probability survey of sexual behaviours
}

\author{
Nathalie Bajos, research director, ${ }^{1,2,3}$ honorary professor, ${ }^{4}$ Kaye Wellings, professor, ${ }^{4}$ Caroline Laborde, \\ research assistant, ${ }^{1,2,3}$ Caroline Moreau, research fellow, ${ }^{1,2,3}$ for the CSF Group
}

${ }^{1}$ INSERM (Institut National de la Santé et de la Recherche

Medicale), CESP Centre for Research in Epidemiology and

Population Health, U1018, Gender Sexual and Reproductive Health Team, F-94276, Kremlin Bicetre, France

${ }^{2}$ Université Paris Sud 11, UMRS 1018, F-94807, Villejuif, France

${ }^{3}$ Institut National des Etudes Demographiques, F-75020, Paris

${ }^{4}$ London School of Hygiene and Tropical Medicine, Department of Public Health and Policy, London WC1E 7HT

Correspondence to: N Bajos nathalie.bajos@inserm.fr

Cite this as: $B M J$ 2010;340:c2573 doi:10.1136/bmi.c2573

\section{ABSTRACT}

Objectives To analyse the association between body mass index (BMI) and sexual activity, sexual satisfaction, unintended pregnancies, and abortions in obese people and to discuss the implications for public health practices, taking into account the respondents' and their partners' BMI.

Design Random probability survey of sexual behaviours. Setting National population based survey of 12364 men and women aged 18-69 living in France in 2006.

Participants Random selection of 5535 women and 4635 men, of whom 3651 women and 2725 men were normal weight (BMI 18.5-<25), 1010 women and 1488 men were overweight (BMI 25-く30), and 411 women and 350 men were obese (BMI >30).

Results Obese women were less likely than normal weight women to report having a sexual partner in the past 12 months (odds ratio $0.71,95 \%$ confidence interval 0.51 to 0.97 ). Obese men were less likely than normal weight men to report more than one sexual partner in the same period $(0.31,0.17$ to $0.57, \mathrm{P}<0.001)$ and more likely to report erectile dysfunction $(2.58,1.09$ to $6.11, P<0.05)$. Sexual dysfunction was not associated with BMI among women. Obese women aged under 30 were less likely to seek healthcare services for contraception $(0.37,0.18$ to $0.76)$ or to use oral contraceptives $(0.34,0.15$ to 0.78$)$. They were also more likely to report an unintended pregnancy (4.26, 2.21 to 8.23).

Conclusion There is a link between BMI and sexual behaviour and adverse sexual health outcomes, with obese women less likely to access contraceptive healthcare services and having more unplanned pregnancies. Prevention of unintended pregnancies among these women is a major reproductive health challenge. Healthcare professionals need to be aware of sensitivities related to weight and gender in the provision of sexual health services.

\section{INTRODUCTION}

Obesity is emerging as one of the fastest growing pandemics in modern times. The current economic downturn might lead to reduced nutritional quality and physical activity, further increasing the prevalence of obesity and related health costs in the coming years. ${ }^{12}$ The adverse effects of obesity on health are, for the most part, well documented. ${ }^{3}$ The consequences for sexual health, however, are less well understood. ${ }^{45}$ Obesity is associated with erectile dysfunction in men, ${ }^{6-9}$ but the evidence in relation to other sexual health outcomes has been equivocal. Some surveys have reported a higher prevalence of sexually transmitted infections among obese people. ${ }^{10-12}$

To date, there have been no comprehensive population based studies of the impact of overweight and obesity on sexual activity and sexual health outcomes such as sexual satisfaction, unintended pregnancy, and abortion. Most research has focused on sexual dysfunction and has been conducted among clinical samples of aging or morbidly obese men. ${ }^{291314}$ There have been few studies on women. ${ }^{15-18}$

The French national survey of sexual behaviours contains questions on sexual partnerships and sexual practices, sexual satisfaction and sexual norms, unwanted pregnancy, abortion, and sexually transmitted infections and is unique in collecting data on weight and height for both respondents and their sexual partners. We investigated sexual behaviours and sexual health by body mass index (BMI) and the implications for public health practices. Our primary goal was not to provide estimates of sexual behaviour of obese people but to compare sexual health behaviours and risks between obese and normal weight individuals on the one hand, and between overweight and normal weight individuals on the other hand. Our hypothesis was that overweight individuals, especially obese people, could be at greater risk of negative sexual outcomes compared with normal weight individuals because of social stigma and lack of adequate medical follow-up. We further hypothesised that the effect of BMI on sexual health outcomes would be different between men and women because the social stigma of overweight and obesity is stronger in women. ${ }^{19-22}$

\section{METHODS}

\section{Sampling design}

The CSF (Contexte de la Sexualité en France) survey was a national random population based survey of 
Table 1|Indicators used in analysis of sexual behaviours

\begin{tabular}{|c|c|}
\hline Topic & Question \\
\hline \multicolumn{2}{|l|}{ Sexual behaviour } \\
\hline Sexual partners 12 months & How many men/women have you had sex with in the past 12 months? \\
\hline Sexual partners and the internet & Have you ever met a sexual partner through the internet? (yes/no) \\
\hline Frequency of sex & On average, how many times have you had sexual intercourse in the past month? \\
\hline Satisfaction of sexual life & Are you satisfied with your current sexual life? (very/rather/rather not/not at all) \\
\hline Importance of sexuality & $\begin{array}{l}\text { Is sexuality important for your personal equilibrium? (essential/important but not essential/not very important/ } \\
\text { not important at all) }\end{array}$ \\
\hline \multicolumn{2}{|l|}{ Reproductive health } \\
\hline Unplanned pregnancy & Have you ever had an unplanned pregnancy? (yes/no) \\
\hline Abortion & Have you had an abortion in the past five years? (yes/no) \\
\hline Contraception & $\begin{array}{l}\text { Did you use anything to prevent pregnancy the last time you had sexual intercourse? Which method did you } \\
\text { use? }\end{array}$ \\
\hline Condom & Have you ever used a condom in the past 12 months? (yes/no) \\
\hline Medical attendance & Have you seen a doctor in the past 12 months about contraception? (yes/no) \\
\hline Sexually transmitted infection (STI) & Have you had a sexually transmitted disease in the past five years? What was it? (list of STIs to be read) \\
\hline \multicolumn{2}{|l|}{ Sexual dysfunction } \\
\hline \multicolumn{2}{|c|}{ In the past 12 months, have you ever... (often/rarely/sometimes/never): } \\
\hline Men & Experienced premature ejaculation? Experienced erectile dysfunction? Had a lack of sexual desire? \\
\hline Women & Had an arousal dysfunction? Experienced painful intercourse? Had a lack of sexual desire? \\
\hline Chronic disease & $\begin{array}{l}\text { Have you got any disease or health problem that is chronic or long term? Is it: cardiovascular problem, back or } \\
\text { joint troubles, depressive problems, diabetes? }\end{array}$ \\
\hline Limitation of activity & Are you limited in your daily activities because of health problems? (yes/no) \\
\hline
\end{tabular}

sexual behaviours. The sample comprised 12364 French speaking men $(n=5540)$ and women $(n=6824)$ aged 18-69 living in France who were interviewed by telephone between September 2005 and March 2006. Two pilot surveys were undertaken in November 2004 and in June 2005 to test the questionnaire and the sampling design.

Participants were informed that the survey was anonymous. The interviewer did not know the telephone number he or she was calling and the telephone numbers were deleted from the interview data file immediately after the first question was answered. The research team trained interviewers for two days. Researchers were present every day to listen to the interviews.

Participants were selected with a two stage probability sampling design, post-stratified for age. An initial sample of households was randomly selected from the telephone directory. One eligible respondent per household was then selected with the next birthday method. In addition, we randomly selected a subsample of people who exclusively used mobile phones to achieve adequate representation of the population. Of those who initially selected, $74.6 \%$ agreed to complete the questionnaire. At the end of the interview, 4957 individuals aged 18-44 were asked to participate in a complementary module (response rate $76 \%$ ) involving a chlamydia screening test carried out at the person's home (a vaginal smear test in women and a urine test in men).

\section{Questionnaire}

The mean duration of the interviews was 49 minutes. Information collected included the sociodemographic and health related characteristics of respondents and their living partners, including weight, height, living conditions, and chronic health problems. Respondents who had ever had sexual intercourse were asked about their partnership histories, including the total number of sexual partners and the number of partners in recent periods, their sexual practices, non-consensual sexual relations, health seeking behaviours, use of contraception, sexual problems, and sexually transmitted infections (table 1).

\section{Variables}

We used the WHO classification of BMI (weight $(\mathrm{kg}) /$ (height $(\mathrm{m})^{2}$ ) and distinguished four categories: underweight $(\mathrm{BMI}<18.5)$, normal weight $(18.5-<25)$, overweight $(25-<30)$, and obese $(\geq 30)$.

\section{Statistical analysis}

From the initial sample of 12364 people, a randomly selected 10170 completed a more detailed questionnaire that collected information on weight and height. This was our group for analyses (4635 men and 5535 women). Pregnant women were excluded from the analysis. Analyses were performed separately for men and women because of sex differences in the associations between obesity and specific sexual behaviours.

We used logistic regression models to test for the effect of obesity and overweight on sexual and contraceptive behaviours in obese and overweight men and women compared with men and women with normal BMI. In multivariate logistic regression models we included those variables significant at $\mathrm{P}<0.25$ in univariate analysis (that is, education, living as a couple, health insurance, income, chronic disease, limitation of activity, number of lifetime sexual partners). We also 
looked at trends over BMI to test the hypothesis that there is a linear relation between BMI and sexual outcomes. In some cases, however, the relations seemed non-linear so we added a polynomial term $\left(\mathrm{BMI}^{2}\right)$ to account for the non-linearity of the associations.

Our estimates were weighted to take into account unequal probabilities of selection in the survey. These probabilities depended on the number of eligible people in the household and on the age of the respondent (we oversampled those aged under 25 to study sexual risk practices at sexual debut). ${ }^{23}$ Weights were equal to the inverse of the probability of being selected in the sample, as used for Horwitz-Thompson estimators. $^{24}$ Post-stratification weights were then applied to adjust the sample to marginal distributions of sex, age, level of education, and region according to the census data to limit non-participation bias. ${ }^{25}$ The composition of the final sample corresponded well to that of the French population as described in the most recent national census. ${ }^{23}$

We present weighted estimates of percentages, means, and odds ratios and unweighted numbers of individuals who answered the questions. All univariate and multivariate analyses were performed with the svy command in Stata 10SE, which takes into account the sampling design for point estimates and variance estimation, with the Taylor linearisation method.

Although we present repeated analyses, we chose not to adjust for multiple comparisons in our study. Indeed, these adjustments increase the frequency of incorrect statements asserting no relation when in fact the association in the data is not a result of chance. ${ }^{26}$ Our analysis is based on a theoretical framework on gender inequalities and builds on existing empirical studies. Therefore, we believe that the universal null hypothesis is unlikely to apply to our study. The reported $\mathrm{P}$ values should nevertheless be interpreted with caution because of multiple comparisons. They should be considered as merely indicative of likely relations between BMI and sexual activity and health.

Table 2 | Distribution of BMI of 4246 women and 3376 men in stable heterosexual relationship (unweighted, that is, number of individuals who responded to survey) and their sexual partners (weighted percentages to take account of sampling design)

\begin{tabular}{lccccc} 
& \multicolumn{3}{c}{ Partners (\%) } \\
\cline { 2 - 5 } Women (with male partner) & Underweight & Normal & Overweight & Obese & Total \\
\hline Underweight (n=335) & 2.4 & 73.6 & 23.0 & 1.0 & 100 \\
\hline Normal (n=2829) & 0.5 & 60.1 & 33.6 & 5.8 & 100 \\
\hline Overweight (n=781) & 1.2 & 38.5 & 47.5 & 12.8 & 100 \\
\hline Obese (n=301) & 0.4 & 32.7 & 44.0 & 22.9 & 100 \\
\hline Total (n=4246) & 0.8 & 53.9 & 36.9 & 8.5 & 100 \\
\hline Men (with female partner) & & & & & \\
\hline Underweight (n=28) & 23.6 & 45.1 & 27.4 & 3.9 & 100 \\
\hline Normal (n=1911) & 12.0 & 74.9 & 10.6 & 2.6 & 100 \\
\hline Overweight (n=1171) & 6.0 & 69.6 & 19.9 & 4.5 & 100 \\
\hline Obese $(n=266)$ & 5.5 & 55.1 & 31.1 & 8.3 & 100 \\
\hline Total $(n=3376)$ & 9.1 & 70.6 & 16.4 & 3.9 & 100 \\
\hline
\end{tabular}

\section{RESULTS}

General characteristics

A total of $9 \%$ of 5535 women and $9 \%$ of 4635 men were obese $(\mathrm{BMI} \geq 30) ; 21 \%$ of women and $35 \%$ of men were overweight (BMI 25-29), and 63\% of women and $54 \%$ of men were of normal weight (BMI 18.5-24).

Respondents who were obese differed from normal weight individuals (BMI 18.5-24) in terms of age, level of education, and medical condition. We found no differences according to cohabitation status or parity. Individuals categorised as obese were significantly older (mean age in obese $v$ normal weight $48.5 v 41.1$, $\mathrm{P}<0.001$, in women, and $50.2 v 37.7, \mathrm{P}<0.001$, in men). They were also more likely to have no education beyond 16 years (odds ratio 3.31 (95\% confidence interval 2.42 to 4.63 ) for women and 2.81 (1.89 to 4.18) for men).

After we controlled for age, obese respondents were more likely to have chronic disease (such as diabetes, cardiovascular disease, depression, or back pain) (odds ratios 1.85 (1.45 to 2.37) for women and 1.85 (1.40 to 2.44) for men). After adjustment for age and chronic disease, obese women were more likely to report being physically limited in their daily activities (1.97, 1.46 to 2.66). This was not so in the case of obese men.

Half of 411 obese women (51\%) and a quarter of 350 obese men considered themselves to be "very overweight" $(\mathrm{P}<0.001)$. In addition, a third of 3651 women $(34 \%)$ with normal BMI thought they were somewhat overweight compared with $11 \%$ of 2725 men $(\mathrm{P}<0.001)$.

Among those with a regular heterosexual partner, the BMI of the two partners was strongly correlated (table 2). The association was stronger for obese women than for obese men; $67 \%$ of obese women reported a weight and height for their partner indicating that he was overweight or obese compared with $39 \%$ of obese men $(\mathrm{P}<0.001)$.

\section{BMI and sexual activity}

After adjustment for potential confounding factors (age, education level, chronic disease, and limitation of daily activity), obese women were 30\% less likely than normal weight women to report a sexual partner in the past 12 months $(0.71,0.51$ to 0.97$)$. Obese women were as likely as normal weight women to be living with a sexual partner in the past 12 months but were significantly less likely to have an occasional sexual partner (data not shown). The same was not true for women who were overweight. Results showed no association between obesity or being overweight and having a sexual partner in the past 12 months among men (table 3). Nonetheless, obese and overweight men were about $70 \%$ and $30 \%$, respectively, less likely to report more than one sexual partner in the past 12 months (table 3). In fact, the likelihood of reporting more than one sexual partner in the past 12 months decreased with increasing $\mathrm{BMI}(\mathrm{P}=0.003$ for women and $\mathrm{P}=0.001$ for men).

Obese women aged 18-29 were three times as likely to report having met a sexual partner through the 
Table $3 \mid$ Sexual behaviours by BMI status. Numbers are unweighted-that is, number of individuals who responded to the survey. Percentages are weighted to account for sampling design

\begin{tabular}{|c|c|c|c|c|c|c|c|}
\hline & \multirow[b]{2}{*}{ Underweight } & \multirow[b]{2}{*}{ Normal } & \multirow[b]{2}{*}{ Overweight } & \multirow[b]{2}{*}{ Obese } & \multirow[b]{2}{*}{ Total } & \multicolumn{2}{|c|}{ Adjusted* odds ratio $(95 \% \mathrm{Cl})$} \\
\hline & & & & & & Obese $v$ normal & Overweight $v$ normal \\
\hline No of women & 463 & 3651 & 1010 & 411 & 5535 & - & - \\
\hline No of men & 72 & 2725 & 1488 & 350 & 4635 & - & - \\
\hline
\end{tabular}

$\%$ with sexual partners in past 12 months (all)†

Women

\begin{tabular}{lccccccc}
\hline At least 1 & 86.9 & 88.1 & 86.3 & 80.0 & 86.9 & $0.71(0.51$ to 0.97$)$ & $1.06(0.83$ to 1.36$)$ \\
\hline 1 partner & 14.1 & 8.3 & 4.4 & 3.3 & 7.4 & $0.61(0.34$ to 1.10$)$ & $0.76(0.54$ to 1.08$)$ \\
\hline Same sex partner & 1.1 & 1.1 & 0.3 & 0.3 & 0.8 & $0.25(0.06$ to 1.14$)$ & $0.36(0.12$ to 1.04$)$ \\
\hline Men & & & & & & & \\
\hline At least 1 & 77.5 & 90.8 & 92.9 & 88.4 & 91.1 & $0.67(0.41$ to 1.10$)$ & $1.12(0.82$ to 1.533$)$ \\
\hline Same sex partner & 15.8 & 16.1 & 8.2 & 3.6 & 12.2 & $0.31(0.17$ to 0.57$)$ & $0.66(0.51$ to 0.86$)$ \\
\hline
\end{tabular}

$\%$ who met sexual partners through internet (all)

\begin{tabular}{lccccccc}
\hline Women aged 18-29 & 2.1 & 5.3 & 9.2 & 17.8 & 6.0 & $4.84(1.86$ to 12.64$)$ & $1.88(0.94$ to 3.75$)$ \\
\hline Men aged 18-29 & 8.8 & 9.9 & 14.1 & 4.1 & 10.4 & $0.38(0.08$ to 1.86$)$ & $1.38(0.76$ to 2.48$)$
\end{tabular}

$\%$ with no sexual intercourse in past month (in respondents who had sex in past 12 months)

\begin{tabular}{llllllll}
\hline Women & 17.6 & 13.5 & 14.9 & 17.8 & 14.5 & $1.19(0.82$ to 1.74$)$ & $1.17(0.85$ to 1.46$)$ \\
\hline Men & 34.3 & 16.5 & 12.4 & 14.1 & 15.1 & $0.97(0.62$ to 1.52$)$ & $1.03(0.78$ to 1.35$)$ \\
\hline
\end{tabular}

Mean frequency of sexual intercourse/month (in respondents who had sex in past 12 months)

\begin{tabular}{|c|c|c|c|c|c|c|c|}
\hline Women & 9.04 & 8.78 & 8.2 & 7.74 & 8.6 & 0.87 (0.64 to 1.19$)$ & $1.11(0.89$ to 1.37$)$ \\
\hline Men & 5.99 & 9.28 & 8.06 & 7.81 & 8.64 & $0.95(0.69$ to 1.30$)$ & $0.99(0.82$ to 1.19$)$ \\
\hline \multicolumn{8}{|c|}{$\%$ very satisfied with their sexual life (all) } \\
\hline Women & 39.6 & 43.9 & 46.4 & 43.2 & 44.1 & $1.07(0.73$ to 1.56$)$ & $1.11(0.86$ to 1.43$)$ \\
\hline Men & 14.0 & 35.7 & 34.5 & 38.3 & 35.3 & 1.25 (0.84 to 1.88$)$ & $0.92(0.72$ to 1.17$)$ \\
\hline \multicolumn{8}{|c|}{$\%$ for whom sexuality is not important for personal equilibrium (all) } \\
\hline Women & 14.7 & 12.3 & 17.0 & 29.1 & 15.0 & $1.96(1.41$ to 2.71$)$ & $1.13(0.87$ to 1.47$)$ \\
\hline Men & 19.6 & 7.5 & 8.5 & 14.3 & 8.7 & 1.54 (0.96 to 2.47$)$ & $1.05(0.75$ to 1.48$)$ \\
\hline
\end{tabular}

*Adjusted for age, living as couple, chronic disease, education, limitation of activity. For satisfaction with sexual life and importance of sexuality, we also adjusted for having sex or not in past 12 months.

†Not adjusted for living as couple as this variable is too collinear with having one partner in past year.

internet than those with a normal BMI. The same was not true for overweight women. The likelihood of having met a partner through the internet, however, significantly increased with BMI $(\mathrm{P}=0.001)$. Obese women were also twice as likely to report having seen a pornographic film in the past 12 months. These associations were not observed among overweight women and among men.

Among those with a sexual partner in the past year, $14 \%$ of women (4871) and 15\% of men (4265) reported no sexual intercourse in the past month, with no difference according to BMI status. Likewise, among individuals who had a partner at the time of the survey, results showed no variation in the frequency of sexual intercourse (table 3), in the length of last sexual intercourse, or in their sexual practices in the past 12 months (data not shown) according to the respondent's BMI.

Obese women were only half as likely to consider that sexuality was important for their "personal life balance" than normal weight women $(\mathrm{P}<0.001)$. The difference was not significant for overweight women, but the results show a significant trend towards lesser importance of sex for personal life balance with increasing $\mathrm{BMI}(\mathrm{P}=0.005)$. The difference was less marked and not significant $(\mathrm{P}=0.07)$ for obese men, who were $60 \%$ less likely to consider sexuality an important component of their "personal life balance." Results also indicate that obese women were less interested in sex than obese men $(2.57,1.59$ to 4.21$)$.

Forty four percent of women and $35 \%$ of men reported they were very satisfied with their sexual life, with no difference across BMI status.

\section{BMI and sexual health}

There was no difference in sexual dysfunction (lack of sexual desire, arousal, painful intercourse) between obese or overweight women compared with women with a normal BMI (table 4). Nevertheless, results show a significant trend towards decreasing sexual desire with increasing $\mathrm{BMI}(\mathrm{P}=0.01)$. Data also show a significant increase in erectile dysfunction with increasing BMI for men $(\mathrm{P}=0.002)$ (table 5). Compared with normal weight men, the odds of often experiencing erectile dysfunction in the past 12 months were 2.58 among obese men $(\mathrm{P}=0.03)$ and 2.69 among overweight men $(\mathrm{P}=0.02)$.

The odds of reporting an unintended pregnancy or an abortion were four times higher among obese women aged under 30 than in normal weight women 
Table $4 \mid$ Weighted percentage of women who often experienced particular sexual dysfunction and BMI in women who had had sex in past 12 months

\begin{tabular}{|c|c|c|c|c|c|c|c|}
\hline & \multirow[b]{2}{*}{ Unweighted total } & \multicolumn{2}{|c|}{ Painful intercourse } & \multicolumn{2}{|c|}{ Lack of sexual desire } & \multicolumn{2}{|c|}{ Arousal dysfunction } \\
\hline & & $\%$ & Adjusted OR* & $\%$ & Adjusted OR* & $\%$ & Adjusted $\mathrm{OR}^{\star}$ \\
\hline Normal & 3264 & 2.1 & 1.00 & 6.9 & 1.00 & 7.5 & 1.00 \\
\hline Overweight & 862 & 1.5 & 0.71 (0.34 to 1.50$)$ & 6.1 & 0.70 (0.48 to 1.03$)$ & 6.2 & $0.82(0.57$ to 1.18$)$ \\
\hline Total & 4871 & 2.0 & - & 6.9 & - & 7.5 & - \\
\hline
\end{tabular}

*Adjusted for age, living as couple, chronic disease, education, limitation of activity.

in the same age group (table 6). We found no significant association for overweight women, but the likelihood of reporting an unintended pregnancy $(\mathrm{P}=0.001)$ or an abortion $(\mathrm{P}=0.035)$ significantly increased with BMI among women aged under 30 . Obese women were also less likely to have seen a doctor for contraception in the past 12 months $(0.37,0.18$ to 0.76 , for those aged $18-29$ and $0.37,0.24$ to 0.57 , for those aged 30-49). There was no significant difference in the use of any method of contraception by BMI status, but obese women were $70 \%$ less likely to report using the pill and eight times more likely to use less effective methods, such as withdrawal, compared with women with normal BMI (table 6). Overweight women were less likely to have used condoms in the past 12 months than normal weight women $(\mathrm{P}=0.04)$. Results show a significant decrease in the use of oral contraception $(\mathrm{P}=0.03)$ and the use of condoms $(\mathrm{P}=0.002)$ and, conversely, an increase in the use of withdrawal $(\mathrm{P}=0.017)$ with increasing BMI among women aged under 30 .

Obese women were as likely to report a sexually transmitted infection in the past five years as women with a normal BMI (table 6), but obese men aged under 30 had a higher prevalence of self reported sexually transmitted infections in the past five years $(\mathrm{P}=0.005)$ (table 7). Obese men aged 30-49 with more than one sexual partner were less likely to have used condoms in the past 12 months than normal weight men $(\mathrm{P}<0.05)$. These associations were not true for overweight men.

\section{DISCUSSION}

The data from this French national survey of sexual behaviours show interesting links between BMI and both sexual behaviour and adverse sexual health outcomes and the importance of some of these issues for obese people, especially women. For men and women alike, obesity seems to affect the number of sexual partners in the past 12 months and, for women, on whether they have a sexual partner at all. Once with a sexual partner, obese and overweight women and men seem no different from others in terms of frequency of sexual intercourse and sexual practices, a finding consistent with other research. ${ }^{27}$ In men, higher BMI was associated with an increased likelihood of sexual dysfunction and obesity was associated with unsafe sexual behaviours and sexually transmitted infections. Obese women were less likely to use effective methods of contraception, especially the pill, and experienced more unintended pregnancies and abortions. They were also less likely to attend contraceptive healthcare services.

The data show a marked gender effect. The partners of obese men and women were more likely themselves to be obese, but the association was stronger for women than for men. There was also evidence that self image varies with gender; obese women were twice as likely to see themselves as such compared with obese men. They also downgraded the importance of sexuality to their wellbeing, which might reflect a rationalising adjustment to the lack of an available sexual partner.

\section{Strengths and limitations}

We had to rely on self reported, rather than objectively measured, weight. Compared with results from a national nutrition survey in France, where weight and height were objectively measured, ${ }^{28}$ we found a lower prevalence of obesity for both men and women. Other studies have noted underestimation of weight in self

Table 5 |Weighted percentage of men who often experienced particular sexual dysfunction and BMI in those who had had sex in past 12 months

\begin{tabular}{|c|c|c|c|c|c|c|c|}
\hline & \multirow[b]{2}{*}{ Unweighted total } & \multicolumn{2}{|c|}{ Premature ejaculation } & \multicolumn{2}{|c|}{ Lack of sexual desire } & \multicolumn{2}{|c|}{ Erectile dysfunction } \\
\hline & & $\%$ & Adjusted $O R^{\star}$ & $\%$ & Adjusted OR* & $\%$ & Adjusted OR* \\
\hline Underweight & 58 & 18.8 & 3.78 (1.33 to 10.80$)$ & 9.4 & 11.48 (3.15 to 41.88$)$ & 0.8 & $0.86(0.10$ to 7.1$)$ \\
\hline Normal & 2504 & 6.0 & 1.00 & 1.4 & 1.00 & 1.2 & 1.00 \\
\hline Overweight & 1387 & 6.7 & 0.89 (0.61 to 1.28$)$ & 2.0 & $1.25(0.67$ to 2.36$)$ & 3.8 & 2.69 (1.46 to 4.95$)$ \\
\hline Obese & 316 & 6.9 & $0.84(0.45$ to 1.60$)$ & 3.3 & $1.88(0.78$ to 4.57$)$ & 5.4 & $2.58(1.09$ to 6.11$)$ \\
\hline Total & 4265 & 6.5 & - & 1.9 & - & 2.5 & - \\
\hline
\end{tabular}

*Adjusted for age, living as couple, chronic disease, education, limitation of activity. 
Table 6|BMI and sexual and reproductive health in women by age. Numbers in each group are unweighted-that is, number of individuals who responded to the survey. Percentages are weighted to account for sampling design

\begin{tabular}{|c|c|c|c|c|c|c|c|}
\hline \multirow[b]{2}{*}{ Age } & \multirow{2}{*}{$\begin{array}{l}\text { Underweight } \\
\quad(n=463)\end{array}$} & \multirow{2}{*}{$\begin{array}{c}\text { Normal } \\
(n=3651)\end{array}$} & \multirow{2}{*}{$\begin{array}{l}\text { Overweight } \\
(n=1010)\end{array}$} & \multirow{2}{*}{$\begin{array}{c}\text { Obese } \\
(n=411)\end{array}$} & \multirow{2}{*}{$\begin{array}{c}\text { Total } \\
(n=5535)\end{array}$} & \multicolumn{2}{|c|}{ Adjusted* odds ratio } \\
\hline & & & & & & Obese $v$ normal & Overweight $v$ normal \\
\hline \multicolumn{8}{|c|}{$\%$ with unplanned pregnancy over lifetime: } \\
\hline $18-29$ & 13.6 & 13.3 & 20.1 & 43.5 & 15.7 & $4.26(2.21$ to 8.23$)$ & $1.48(0.88$ to 2.50$)$ \\
\hline $30-49$ & 30.4 & 34.2 & 37.8 & 36.4 & 34.8 & $1.03(0.67$ to 1.59$)$ & $1.16(0.87$ to 1.54$)$ \\
\hline \multicolumn{8}{|c|}{$\%$ with abortion in past five years: } \\
\hline $18-29$ & 5.0 & 6.1 & 6.6 & 22.4 & 6.8 & $3.72(1.59$ to 8.70$)$ & $0.93(0.42$ to 2.10$)$ \\
\hline $30-49$ & 6.4 & 4.3 & 4.4 & 6.4 & 4.6 & 2.01 (1.01 to 4.00$)$ & 1.23 (0.64 to 2.37$)$ \\
\hline \multicolumn{8}{|c|}{$\%$ who used contraception at last sexual intercourse among those who did not want to get pregnant: } \\
\hline \multicolumn{8}{|l|}{ None: } \\
\hline $18-29$ & 5.3 & 3.1 & 3.8 & 7.6 & 3.6 & $2.48(0.69$ to 8.93$)$ & 1.07 (0.37 to 3.08$)$ \\
\hline $30-49$ & 6.6 & 7.0 & 6.0 & 8.5 & 6.9 & 1.18 (0.50 to 2.81$)$ & $0.92(0.51$ to 1.66$)$ \\
\hline \multicolumn{8}{|l|}{ Pill: } \\
\hline $18-29$ & 79.3 & 78.7 & 71.3 & 58.0 & 77.1 & 0.34 (0.15 to 0.78$)$ & 0.72 (0.42 to 1.22$)$ \\
\hline $30-49$ & 45.7 & 49.1 & 49.4 & 51.6 & 49.0 & 0.91 (0.53 to 1.55$)$ & 0.95 (0.69 to 1.32$)$ \\
\hline \multicolumn{8}{|l|}{ IUD: } \\
\hline $18-29$ & 0.5 & 3.6 & 2.9 & 9.8 & 3.4 & 2.42 (0.60 to 9.78$)$ & 0.41 (0.14 to 1.23$)$ \\
\hline $30-49$ & 26.9 & 30.6 & 33.1 & 29.2 & 30.7 & $1.13(0.60$ to 2.11$)$ & 1.11 (0.78 to 1.56$)$ \\
\hline \multicolumn{8}{|c|}{ Withdrawal: } \\
\hline $18-29$ & 1.3 & 0.9 & 2.9 & 6.7 & 1.41 & 8.51 (2.02 to 35.88$)$ & 2.74 (0.75 to 10.02$)$ \\
\hline $30-49$ & 0.5 & 3.1 & 1.2 & 0.9 & 2.43 & 0.24 (0.03 to 2.20$)$ & 0.36 (0.09 to 1.49$)$ \\
\hline \multicolumn{8}{|c|}{$\%$ who saw doctor in past 12 months for contraceptive issues among those who have had sex in past 12 months $\dagger$ : } \\
\hline $18-29$ & 82.2 & 85.8 & 84.8 & 68.7 & 84.4 & $0.37(0.18$ to 0.76$)$ & $0.84(0.46$ to 1.55$)$ \\
\hline $30-49$ & 78.5 & 79.0 & 75.9 & 57.2 & 76.7 & $0.37(0.24$ to 0.57$)$ & $0.91(0.65$ to 1.28$)$ \\
\hline \multicolumn{8}{|c|}{$\%$ who did not use condom in past 12 months among those with more than one sexual partner: } \\
\hline $18-29$ & 14.4 & 14.0 & 29.3 & 0 & 15.6 & - & $3.78(1.20$ to 11.9$)$ \\
\hline $30-49$ & 14.3 & 44.9 & 61.0 & 54.2 & 43.2 & $0.97(0.23$ to 4.04$)$ & $3.37(1.05$ to 10.8$)$ \\
\hline \multicolumn{8}{|c|}{$\%$ with self reported sexually transmitted infection over past five years (excluding mycoses): } \\
\hline $18-29$ & 3.5 & 4.3 & 2.9 & 2.9 & 3.9 & 0.79 (0.21 to 2.92$)$ & $0.66(0.27$ to 1.61$)$ \\
\hline $30-49$ & 3.7 & 2.0 & 1.4 & 1.1 & 1.9 & 0.89 (0.25 to 3.18$)$ & $1.05(0.41$ to 2.70$)$ \\
\hline \multicolumn{8}{|c|}{$\%$ with Chlamydia trachomatis (biological test): } \\
\hline $18-29$ & 2.4 & 3.4 & 2.0 & 0 & 3.0 & - & $0.47(0.04$ to 5.46$)$ \\
\hline $30-49$ & 0 & 0.9 & 1.3 & 0 & 0.9 & - & $1.34(0.22$ to 8.08$)$ \\
\hline
\end{tabular}

reported data. ${ }^{2930}$ Misclassification of BMI caused by self reporting nevertheless seems to affect all women equally, regardless of $\mathrm{BMI},{ }^{31}$ which would lead to underestimates of the association between exposure and outcome. Misclassification, however, is unlikely to be associated with the reporting of sexual behaviours as height and weight were collected at the beginning of the questionnaire before the topics of sexual behaviours and sexual health were introduced.

Data on health issues were limited in the questionnaire because of time constraints. Further research should include information on comorbidities that could act as mediators of the relation between obesity and sexual activity (such as urinary incontinence, metabolic syndrome, musculoskeletal problems, polycystic ovary syndrome).

We focused on heterosexual relationships to study the impact of high BMI on sexual health outcomes. We hypothesised that social stigma about weight would be higher for women. Furthermore, the number of individuals who reported exclusively same sex partners was too small for us to carry out a specific analysis. Nevertheless, an in depth analysis needs to be done as the impact of obesity on sexually transmitted infections has been documented among gay men, ${ }^{12}$ as well as the impact of lipodystrophy on sexual risk taking among respondents with HIV. ${ }^{32}$ Social stigma about weight, which seems to be related to gender, might be compounded by other specific issues for people whose sexuality could also be socially stigmatised.

\section{Comparison with other studies}

The gender differences we found in terms of sexual partnerships have not been shown in analyses of data from other population based surveys. In the US survey on health and nutrition, for example, obese men and women alike reported fewer sexual partners than nonobese individuals. ${ }^{10}$ Our finding of an increased risk of erectile dysfunction among obese men has been noted in other studies, ${ }^{7-9}$ unlike our finding of no increase in 
Table 7 | BMI and sexual and reproductive health in men by age. Numbers in each group are unweighted-that is, number of individuals who responded to the survey. Percentages are weighted to account for sampling design

\begin{tabular}{|c|c|c|c|c|c|c|c|}
\hline \multirow[b]{2}{*}{ Age } & \multirow{2}{*}{$\begin{array}{l}\text { Underweight } \\
\quad(n=72)\end{array}$} & \multirow{2}{*}{$\begin{array}{c}\text { Normal } \\
(n=2725)\end{array}$} & \multirow{2}{*}{$\begin{array}{c}\text { Overweight } \\
(n=1488)\end{array}$} & \multirow{2}{*}{$\begin{array}{c}\text { Obese } \\
(n=350)\end{array}$} & \multirow{2}{*}{$\begin{array}{c}\text { Total } \\
(n=4635)\end{array}$} & \multicolumn{2}{|c|}{ Adjusted* odds ratio } \\
\hline & & & & & & Obese $v$ normal & Overweight $v$ normal \\
\hline \multicolumn{8}{|c|}{$\%$ with self reported sexually transmitted infection in past five years (excluding mycoses): } \\
\hline $18-29$ & 4.3 & 2.1 & 1.0 & 11.8 & 2.2 & 11.84 (2.15 to 65.33$)$ & $0.57(0.14$ to 2.27$)$ \\
\hline $30-49$ & 3.4 & 1.8 & 1.1 & 1.0 & 1.5 & $0.75(0.09$ to 5.99$)$ & $0.67(0.30$ to 1.54$)$ \\
\hline \multicolumn{8}{|c|}{ \% with Chlamydia trachomatis (biological test): } \\
\hline $18-29$ & 0 & 2.5 & 1.4 & 0 & 2.2 & - & $0.51(0.06$ to 4.42$)$ \\
\hline $30-49$ & 0 & 1.5 & 0 & 0 & 1.0 & - & - \\
\hline \multicolumn{8}{|c|}{$\%$ who did not use condom in past 12 months among those with more than one sexual partner: } \\
\hline $18-29$ & 16.8 & 9.9 & 12.9 & 0.0 & 10.6 & - & $1.67(0.48$ to 5.84$)$ \\
\hline $30-49$ & 0 & 23.6 & 28.6 & 6.3 & 23.5 & $0.06(0.004$ to 0.96$)$ & $0.94(0.40$ to 2.21$)$ \\
\hline
\end{tabular}

*Adjusted for age, living as couple, chronic disease, education, limitation of activity, and number of lifetime sexual partners (except for contraception at last intercourse and condom use in past 12 months).

sexual dysfunction among obese women. A study among women participating in a programme to lose weight showed a lack of sexual desire and difficulties with sexual performances among obese women. ${ }^{18}$ In a case-control study, Esposito et al also found that obese women were more likely to report arousal dysfunction and being less sexually satisfied..$^{33}$ Obese women in our study, however, seemed to minimise the importance of sexuality to their wellbeing. The increased risk of unplanned pregnancy among obese women shown in our study was not found in a US study examining this association, though its focus was not specifically on sexual health. ${ }^{34}$

The relation between obesity and sexual ill health might be forged via physiological, social, and psychological mechanisms. ${ }^{35}$ It is in the social factors influencing sexual behaviour, however, that we are most likely to find insights into these findings, particularly for women. ${ }^{36}$ In industrialised countries, there is considerable evidence that women are under stronger social pressure than men regarding weight. ${ }^{19-2237}$ There is also evidence that men are more likely than women to select their partners according to weight. ${ }^{19-2238}$ Several of our findings - that women in our study were more likely to think that they were too fat, that fewer obese men than women reported having an overweight or obese sexual partner, and that obese women were less likely than obese men to have had a sexual partner in the past 12 months - need to be seen in this context. Psychological factors (such as poor sexual self esteem leading to difficulty in allowing or initiating sex) or biological factors (such as musculoskeletal problems) might also be involved. Nevertheless, low self esteem, although a psychological attribute, derives from social stereotypes around obesity and so is essentially social in origin, though socially different to not being able to find a partner. The greater likelihood that obese women seek partners on the internet, which might increase the chances of finding a partner without surveillance as well as affording possibilities to conceal weight, can also reflect a stronger social pressure regarding weight for women. The lower prevalence of medical consultation for contraception among obese women could also be attributed to concerns over body image and weight.

Preventing unintended pregnancies among obese women is a major reproductive health challenge. Obesity is known to increase the risk of adverse outcomes of pregnancy. ${ }^{39}$ The marked increase in risk of unintended pregnancy, despite lower fecundity in obese women, ${ }^{40}$ reflects not patterns of sexual behaviour but reliance on less effective methods of contraception. Such methods do not generally require medical intervention and so this finding must be seen in tandem with obese women's infrequent attendance at healthcare services for contraception and might, in part, reflect negative feelings towards their fat body. It might also reflect reluctance on the part of healthcare professionals to prescribe oestrogen-progestogen contraceptives for obese women because of concerns over the increased risk of cardiovascular events ${ }^{41}$ (though being overweight remains only category 2 (caution) in the WHO medical eligibility criteria). ${ }^{424}$ Nevertheless, the lower prescription of such contraceptives for obese women does not seem to be compensated for either by greater use of other effective methods such as an intrauterine device or progestogen only methods or by other long acting reversible contraception (which are rarely used in France). Yet these methods would be particularly suitable for obese women given their high efficacy rates and the low risk of associated venous thromboembolism. The lower prevalence of use of hormonal contraception, which persisted after adjustment for chronic disease including cardiovascular risk factors, could also result from women's fear of weight gain, an important reason for women stopping the pill. ${ }^{445}$

\section{Conclusions and policy implications}

The public health impact of these findings is important. The scale of the problem and the magnitude of the effects (particularly the fourfold increase in risk of unintended pregnancy among obese women) warrants focused attention. In terms of targeting advice and care, a considerable proportion of the population is obese, is easily identified as such, and is at increased risk in terms of poorer sexual health status. ${ }^{46}$ Any temptation to think that obese women are less sexually 


\section{WHAT IS ALREADY KNOWN ON THIS TOPIC}

Studies have shown a relation between obesity and erectile dysfunction in men, but the evidence in relation to other sexual health outcomes such as sexual satisfaction, unintended pregnancy, and abortion has been equivocal

Most research has been conducted among clinical samples of ageing or morbidly obese men; few studies have been conducted among women

\section{WHAT THIS STUDY ADDS}

There is a link between BMI and sexual behaviour and adverse sexual health outcomes, in particular an increased likelihood of failing to access contraceptive healthcare services and of unplanned pregnancy in obese women

There is a clear gender effect of BMI on sexual behaviour, and health professionals need to be aware that this can have an impact on sex and relationships and sexual health

active and therefore less in need of effective methods of contraceptive is clearly without foundation.

These data should encourage enhanced awareness of weight on the part of healthcare professionals in the provision of sexual health advice and the careful targeted and tailored advice relating to fertility control, prevention of infection, and psychosexual counselling. Given the social and gender related sensitivities, obese women and men will certainly benefit from tactful guidance and advice on preventive sexual health matters.

We thank the participants in the study. The CSF group includes N Bajos, M Bozon, N Beltzer, A Andro, M Ferrand, V Goulet, A Laporte, C Le Van, H Leridon, S Levinson, N Razafindratsima, L Toulemon, and J Warszawski. Contributors: NB, CM, and KW conceived and wrote the paper. CL carried out the statistical analysis and commented on the first draft of the paper and approved the final version, as did all the other members of the research team. NB is guarantor.

Funding: The survey was funded by the French National Agency of Aids Research (ANRS). The Fondation de France, the Institut National de la Prevention et d'Education pour la Sante, and the Direction de la Recherche des Etudes Economiques et Sociale (DREES) also contributed to funding. The researchers operated independently of the funders. Competing interests: All authors have completed the unified competing interest form at www.icmje.org/coi_disclosure.pdf (available on request from the corresponding author) and declare (1) no financial support for the submitted work from anyone other than their employer; (2) no financial relationships with commercial entities that might have an interest in the submitted work; (3) no spouses, partners, or children with relationships with commercial entities that might have an interest in the submitted work; and (4) no non-financial interests that may be relevant to the submitted work.

Ethical approval: The survey was approved by the French Commission Nationale Informatiques et Libertes (www.cnil.fr/english/). This commission is in charge of examining both ethical and anonymity issues of research protocols. There was no possible linkage between the identity of the respondents, their answers to the questionnaire, and the results of the chlamydia test. Participants who underwent chlamydia testing signed an informed consent agreeing on the anonymous computerised treatment of the data.

Data sharing: No additional data available.

1 Ludwig D, Pollack H. Obesity and the economy. JAMA 2009;301:533-5.

2 Giugliano D, Giugliano F, Esposito K. Sexual dysfunction and the mediterranean diet. Public Health Nutr 2006;9:1118-20.

3 James WPT. The epidemiology of obesity: the size of the problem. J Intern Med 2008;263:336-52.

4 Wingood GM, DiClemente RJ, Harrington K, Davies SL. Body image and African American females' sexual health. I Womens Health Gend Based Med 2002;11:433-9.

5 Kraft C, Robinson BB, Nordstrom DL, Bockting WO, Rosser BR Obesity, body image, and unsafe sex in men who have sex with men. Arch Sex Behav 2006;35:587-95.
6 Adolfsson B, Elofsson S, Rossner S, Undel AL. Are sexua dissatisfaction and sexual abuse associated with obesity? A population-based survey. Obes Res 2004;12:1702-9.

7 Andersen I, Heitman BL, Wagner G. Obesity and sexual dysfunction in younger Danish men. J Sex Med 2008;5:2053-60.

8 Chen JYW, Ng EML. Body mass index, physical activity and erectile dysfunction: a u-shaped relationship from population-based survey. Int J Obes 2007;31:1571-8.

9 Larsen SH, Wagner G, Heitmann BL. Sexual function and obesity. Int J Obes 2007;31:1189-98.

10 Nagelkerke NJ, Bernsen RM, Sgaier SK, Jha P. Body mass index, sexual behaviour, and sexually transmitted infections: an analysis using the NHANES 1999-2000 data. BMC Public Heath 2006;6:199.

11 Wee CC, Huskey KW, McCarthy EP. Obesity and the likelihood of sexual behavioural risk factors for HPV and cervical cancer. Obesity 2008;16:2552-5.

12 Moskowitz DA, Seal DW. Revisiting obesity and condom use in men who have sex with men. Arch Sex Behav 2010;39:761-5.

13 Duval K, Marceau P, Lescelleur O, Hould FS, Marceau S, Biron S, et al. Health-related quality of life in morbid obesity. Obes Surg 2006;16:574-9.

14 Esposito K, Giugliano F, Di Palo C, Giugliano G, Marfella R, D’Andrea $\mathrm{F}$, et al. Effect of lifestyle changes on erectile dysfunction in obese men; a randomized controlled trial. JAMA 2004;291:2978-84.

15 Kinzi JF, Trefat E, Fiala M, Hotter A, Biebl W, Aigner F. Partnership, sexuality, and sexual disorders in morbidly obese women: consequences of weight loss after gastric banding. Obes Surg 2001;11:455-8.

16 Bond DS, Vithiananthan S, Leahey TM, Thomas JG, Sax HC, Pohl D, et al. Prevalence and degree of sexual dysfunction in a sample of women seeking bariatric surgery. Surg Obes Relat Dis 2009;5:698-704.

17 Saigal C. Obesity and erectile dysfunction. JAMA 2004;291:3011-2.

18 Kolotkin RL, Binks M, Crosby RD, Ostbye T, Gress RE, Adams TD. Obesity and sexual quality of life. Obesity 2006;14:472-9.

19 Chen JYW, Brown M. Obesity stigma in sexual relationships. Obes Res 2005;13:1393-7.

20 De Saint-Pol T. Norms and attitudes to body fatness: a European comparison. Popul Soc 2009;455:2-4

21 Gremillion H. The cultural politics of body size. Annu Rev Anthro 2005;34:13-32.

22 Reisher E, Koo K. The body beautiful: symbolism and agency in the social word. Annu Rev Anthro 2004;33:297-317.

23 Bajos N, Bozon M. Enquête sur la sexualité en France. Pratiques, genre et santé. La Découverte, 2008. [Sexuality in France. Practices, gender and health. Batwell Press, in press.]

24 Särndal C, Swensson B, Wretman, J. Model assisted survey sampling. Springer-Verlag, 1992

25 Warszawski J, Messiah A, Lellouch J, Meyer L, Deville JC. Estimating means and percentages in a complex sampling survey: application to a French national survey on sexual behaviour (ACSF). Stat Med 1997;16:397-423.

26 Rotman K. No adjustments are needed for multiple comparisons. Epidemiology 1990;1:43-6.

27 Kaneshiro B, Jensen JT, Carison NE, Harvey SM, Nichols MD, Edelman AB. Body mass index and sexual behaviour. Obstet Gynecol 2008;112:586-92.

28 Etude nationale nutrition santé. INVS, 2006.

29 Kuczmarski M, Kuczmarski R, Najjar M. Effects of age on validity of self-reported height, weight and body mass index: findings from the third national health and nutrition examination survey, 1988-1994.) Am Diet Assoc 2001;101:28-34.

30 Nyholm M, Gullberg B, Rastam L, Lindblad U. What is the accurate prevalence of obesity in Sweden in the 21st century? Methodological experiences from the Skaraborg project. Obesity 2008;16:896-8.

31 Brunner Huber LR. Validity of self-reported height and weight in women of reproductive age. Matern Child Health J 2007;11:137-44.

32 Desquilbet L, Deveau C, Goujard C, Hubert JB, Derouineau J, Meyer L, PRIMO Cohort Study Group. Increase in at-risk sexual behaviour among HIV-1-infected patients followed in the French PRIMO cohort. AIDS 2002;16:2329-33.

33 Esposito K, Ciotola M, Giugliano F, Bisogni C, Schisano B, Autorino R, et al. Association of body weight with sexual function in women. Int I Impot Res 2007;19:353-7.

34 Kaneshiro B, Edelman AB, Carison NE, Nichols MD, Jensen JT. The relationship between body mass index and unintended pregnancy: results from the 2002 National Survey of Family Growth. Contraception 2008;77:234-8.

35 Trischitta V. Relationship between obesity-related metabolic abnormalities and sexual function. J Endocrinol Invest 2003;26:62-4.

36 Jacobson P. Spouse resemblance in body mass index: effects on adult obesity prevalence in the offspring generation. Am J Epidemio 2007;165:101-8. 
37 Chang V, Christakis N. Self-perception of weight appropriateness in the United States. Am J Prev Med 2003;24:332-9.

38 Sobal J, Nicolopoulos V, Lee J. Attitudes about overweight and dating among secondary school students. Int J Obes Relat Metab Disord 1995;19:376-81.

39 Cedergren MI. Maternal morbid obesity and the risk of adverse pregnancy outcome. Obstet Gynecol 2004;103:219-24.

40 Pasquali R, Patton L, Gambineri A. Obesity and infertility. Curr Opin Endocrinol Diabetes Obes 2007;14:482-7.

41 ESHRE Capri Workshop Group. Nutrition and reproduction in women. Hum Reprod Update 2006;12:193-207.

42 World Health Organization. Medical eligibility for contraceptive use. 3rd ed. WHO, 2004.
43 Trussell J, Bimla Schwarz EB, Guthrie K. Obesity and oral contraceptive pill failure. Contraception 2009;79:334-8

44 Larsson G, Blohm F, Sundell G, Andersch B, Milson I. A longitudinal study of birth control and pregnancy outcome among women in a Swedish population. Contraception 1997;56:9-16.

45 Oddens BJ, Visser A, Verner HM, Everaerd AM, Lehert P. Contraceptive use and attitudes in Great Britain. Contraception 1994; $49: 73-86$

46 Shah MB. Obesity and sexuality in women. Obstet Gynecol Clin North Am 2009;36:347-60.

Accepted: 18 April 2010 